\title{
Sobre el concepto de ficción bizantina*
}

\author{
TOMÁS FERNÁNDEZ \\ Conicet-UBA
}

\begin{abstract}
De toutes les oppositions qui divisent artificiellement la science sociale, la plus fondamentale, et la plus ruineuse, est celle qui s'établit entre le subjectivisme et l'objectivisme

P. Bourdieu: Le sens pratique
\end{abstract}

En lo que sigue, (1) se discute brevemente la perspectiva de Kaldellis y otros investigadores modernos en torno a la ficción bizantina; ${ }^{1}(2)$ se propone un abordaje

* Agradezco el financiamiento continuo de Conicet-UBA, que me ha permitido una dedicación exclusiva a la filología y la literatura bizantinas. Para esta investigación, agradezco también a la Humboldt-Stiftung, que me ha permtido acceder a la rica colección bibliográfica de la biblioteca del Historicum, Ludwig-Maximilans-Universität (Múnich). Por comentarios a versiones previas de esta artículo, querría expresar mi agradecimiento a Pablo Cavallero, Marco Caracciolo y Camila Maurer. Por una lectura detallada y valiosos comentarios, al lector anónimo de Ancient Narrative y al Prof. Schmeling.

${ }^{1}$ A. Kaldellis, «The Emergence of Literary Fiction in Byzantium and the Paradox of Plausibility», en P. Roilos (ed.), Medieval Greek Storytelling. Fictionality and Narrative in Byzantium, Wiesbaden, Harrassowitz, 2014, pp. 115-129. Como otros autores, Kaldellis opina que la ficción bizantina surgiría en el siglo XII, junto con la novela. Véase p. 116: «the fictive stance seems to be altogether absent from Byzantine "literature" between the seventh and the twelfth century». Sobre el concepto de fictive stance, véase infra, n. 5. Para el concepto de ficción bizantina a partir del siglo XII - del que, por su problemática específica, este artículo se ocupa sólo al pasar-, cf. la extensa contribución de P.A. Agapitos, «In Rhomaian, Frankish and Persian Lands: Fiction and Fictionality in Byzantium and Beyond», en: P.A. Agapitos - L.B. Mortensen (eds.), Medieval Narratives between History and Fiction, Copenhagen, Museum Tusculanum Press, 2012, pp. 235-367, con las apostillas y contrapuntos aportados por C. Cupane, «Una passeggiata nei boschi narrativi. Lo statuto della finzione nel "Medioevo romanzo e Orientale". In margine a un contributo recente», Jahrbuch der Österreichischen Byzantinistik 63 (2013), pp. 61-90. Véase también la colección editada por C. Cupane y B. Krönung, Fictional Storytelling in the Mediterranean Eastern Mediterranean and Beyond, Leiden - Boston, Brill, 2016; y la editada por Ch. Messis - M. Mullett - I. Nilsson, Storytelling in Byzantium. Narratological Approaches to Byzantine texts and images, Uppsala, Uppsala Universitet, 2018. I. Nilsson es, 
diferente, que pone el acento en los procedimientos y rasgos narrativos; (3) se lleva a cabo un estudio de caso, realizado de acuerdo a dicho abordaje; (4) se presentan ciertas modalidades de la creencia bizantina, crucial en un estudio como el de Kaldellis; (5) se concluye con una breve discusión sobre el concepto de ficción bizantina.

1. Para definir la ficción, bizantina u otra, suele ponerse el acento en su particular relación con el referente externo. Esta perspectiva presenta distintas formas. En su modo más crudo la ficción, por no corresponderse con el mundo exterior, es equiparada con la falsedad y la mentira. Otra perspectiva no la considera exactamente falsa, pero subraya que carece de cualquier valor de verdad; así, en términos de G. Frege, la ficción (Dichtung) tiene sentido (Sinn) pero no denotación (Bedeutung). Una versión algo distinta postula la intransitividad de la ficción, en el sentido de Genette: ${ }^{2}$ niega la pertinencia del referente en ficción pero, al hacerlo, subraya la centralidad que este referente sigue poseyendo, en la medida en que el texto se caracteriza por su vacance thématique; por vía negativa, el referente sigue siendo ineludible, como la noción de la divinidad en la definición del ateo. Una comparación con la no ficción puede ser instructiva para ilustrar este punto: en la historiografía, verbigracia, y al menos desde la perspectiva tradicional, ${ }^{3}$ la relación con la «realidad» puede ponerse a prueba; en efecto, los relatos fácticos pueden someterse a un juicio de verdad, mientras la ficción no es verdadera ni falsa: «Fictional discourse is different in kind from factual: its statements (and other

se sabe, pionera de los estudios narratológicos en el ámbito bizantino. Véase su Erotic Pathos, Rhetorical Pleasures. Narrative Technique and Mimesis in Eumathios Makrembolites' Hysmine \& Hysminias, Uppsala, Acta universitatis Upsaliensis, 2001, así como su más reciente Raconter Byzance: la littérature au XIIe siècle, Paris, Les Belles Lettres, 2014.

${ }^{2}$ El texto de ficción es «intransitif d'une manière qui [...] tient [...] au caractère fictionnel de son objet, qui détermine une fonction paradoxale de pseudo-référence, ou de dénotation sans dénoté»; G. Genette, Fiction et diction, Paris, Seuil, 1991, p. 36. Más en general, un texto es intransitivo en tanto intraducible en otros términos, por tener una «significación inseparable de su forma verbal» (ibid., pp. 35-36). Críticas razonables contra el criterio de definir la ficción por su relación inestable y fluida con el referente pueden encontrarse en P. Lamarque - S.H. Olsen, Truth, Fiction, and Literature. A Philosophical Perspective, Oxford, Clarendon Press, 1994, e.g. p. 33; para una discusión más amplia de la cuestión, cf. R. Walsh, The Rhetoric of Fictionality, Columbus, Ohio State University Press, 2007, especialmente pp. 38-51.

${ }^{3}$ El gran interés del experimento teórico de Hayden White consiste, precisamente, en considerar los textos historiográficos como intransitivos; cf. infra, n. 74. 
forms of expression) do not constitute truth-telling or lying, and in this sense fiction has no truth-status. $\rangle^{4}$

Anthony Kaldellis, por su parte, define la especificidad de la ficción bizantina por una «postura ficticia» (fictive stance) compartida por autor y lector, en la cual la obra en cuestión «is not meant to be evaluated by criteria of historical accuracy». ${ }^{5}$ Esta ingeniosa formulación parece resolver muchos problemas metodológicos a la vez. Por un lado, no sería anacrónica, en tanto toma el punto de vista de los bizantinos y no el del investigador moderno. No sería unilateral, porque se ocupa no sólo del receptor sino también del emisor. No sería meramente subjetiva, porque le importa la «precisión histórica», ni meramente objetivista, porque no le interesa el referente en sí sino el modo en que un sujeto histórico interpreta ese referente (cuya existencia autónoma, por ende, puede soslayarse).

Sin embargo, la preocupación por la «precisión histórica» como tal no es bizantina. La misma fórmula de «precisión histórica» parece una imposición moderna a sujetos pretéritos y, en la medida en que no se explicita su pertinencia, podría pecar de anacronismo, pese a la aparente falta de anacronismo recién subrayada. Kaldellis es consciente de esta yuxtaposición de sujetos y puntos de vista. Así, explica que la historicidad bizantina no se ocupa, como la moderna, de lo «probably accurate» sino de lo «essentially true». ${ }^{6}$ En resumen: la postura ficcional implica que la obra en cuestión no será evaluada según criterios de «precisión histórica»; pero esta «precisión histórica» (que interesa sólo al moderno, para quien lo histórico es lo «probablemente preciso») no tiene en realidad aplicación para el bizantino, que se ocupa, no de la «precisión probable», sino de lo «esencialmente verdadero».

La cuestión de la verdad o falsedad del texto ficticio, expulsada por la puerta, vuelve a entrar por la ventana: no importa la realidad objetiva, pero sí lo que los sujetos (autor y lector) consideran verdadero. Kaldellis, que rechaza explícitamente la relevancia de la historicidad objetiva para definir la ficción, estima que

${ }^{4}$ C. Gill, «Plato on Falsehood-not Fiction», en C. Gill - T.P. Wiseman (eds.), Lies and Fiction in the Ancient World, Exeter, University of Texas Press, 1993, pp. 38-87, aquí p. 39. La afirmación de este mismo autor en p. 40 («The distinction between factual and fictional discourse, which is familiar to us, has no obvious equivalent in Plato's framework») podría extenderse a muchos otros autores y períodos.

${ }^{5}$ Kaldellis, «Emergence», p. 115, mis itálicas. La definición completa de fictive stance corre así: «the mode of writing and reading in which it is understood on all sides (by both author and readers) that a particular work is not meant to be evaluated by criteria of historical accuracy» (itálicas del autor).

${ }^{6}$ Kaldellis, «Emergence», p. 120, mis itálicas. Considérese también: «Byzantine readers evaluated historicity with the criteria of "deeper" or "inner" truth» (ibidem, p. 119). 
sí es imprescindible que autor y lector no juzguen un texto según criterios de precisión histórica para considerarlo ficticio.

Un ejemplo concreto muestra cómo el mismo Kaldellis comprende los límites de su conceptualización: la hagiografía simplemente no es ficción porque fue tomada «at face value by contemporary readers». ${ }^{7}$ Aquí quedan definidas varias equivalencias tácitas de su artículo. Ficción es lo que no debe evaluarse según criterios de precisión histórica por un emisor y un receptor dados, pero esta precisión histórica, que en una primera formulación parece depender de la relación real o supuesta entre un texto y su referente según lo interpretan los sujetos que lo consideran, o de unos mecanismos de validación dependientes en última instancia de esta correspondencia, se reduce en su aplicación práctica a lo que el lector, y ya no el autor, toma por cierto.

En esta segunda formulación (lo tomado at face value) no hay mención de los criterios de precisión histórica, mientras que en la primera (la postura ficticia, donde el texto no se evalúa según criterios de precisión histórica) no había mención de la creencia. Entre estas formulaciones, parcialmente incompatibles, existen varias posibilidades lógicas: si el lector cree, necesariamente el texto no será ficticio; si no cree, puede ser ficción (cuando ése es el pacto con el autor) o no (cuando, por ejemplo, sospecha una falsificación o rechaza el pacto).

La historiografía se ha preguntado qué es verdad para el erudito contemporáneo. M. Mullett observa que en el mundo bizantino «the saint's life [...] had a close relationship to fiction»; uno de las misiones de los bolandistas fue «to weed the chaff from the straw and present truly credibly saints for the Church». ${ }^{8}$ Sin duda, también las actas apócrifas o los evangelios apócrifos «recounted events necessary for Christian understanding, without necessarily representing historical accuracy» (nótese la coincidencia con la formulación de Kaldellis). ${ }^{9}$ Mullett destaca la afinidad entre las vidas de santo y la literatura considerada habitualmente ficción, y menciona la posibilidad, al menos teórica, de separar lo ficticio de lo verdadero, considerando ambos desde un punto de vista moderno. Como Kaldellis, acepta la distinción entre precisión histórica y utilidad en la narración, admitiendo que la precisión histórica sólo interesa al investigador moderno.

Quienes leen la hagiografía como historia se interesan, a diferencia de Kaldellis, en distinguir elementos falsos y verdaderos. En este ámbito, no hace tanto tiempo se escuchaban voces como la de Dummer: «Damit ist die hagiographische

\footnotetext{
${ }^{7}$ Kaldellis, «Emergence», p. 116.

${ }^{8}$ M. Mullett, «No Drama, No Poetry, No Fiction, No Readership, No Literature», en L. James (ed.), A Companion to Byzantium, Chichester, Wiley-Blackwell, 2010, pp. 227-238, aquí p. 230.

${ }^{9}$ Mullett, «No Drama», p. 231, mis itálicas.
} 
Überlieferung nach heutigen Gesichtspunkten, von Zwischenzonen abgesehen, im Grunde in historiographisch wertvolles und in historiographisch wertloses Material dividiert». ${ }^{10}$ Esta frase resume la crudeza de cierta percepción moderna, fundada en un pretendido objetivismo, sobre la «realidad» bizantina. Charis Messis afirmó recientemente que, considerado fuera de su texto, «every hagiographic text that is not confirmed by independent sources is a fiction». ${ }^{11}$ Aquí, por supuesto, se cuela la identificación entre falsedad y ficción, de utilidad dudosa. En efecto, la obra historiográfica de un falsario no es ficción. Es simplemente falsa, como admite Kaldellis. ${ }^{12}$ Por su parte, la novela histórica moderna se corresponde en gran medida con un referente externo y sigue siendo considerada ficticia.

En cuanto al problema de tomar at face value, es casi innecesario subrayar que los bizantinos, como los cristianos en general, no tomaron ni siquiera la sagrada escritura al pie de la letra; la lectura literal era una entre varias posibles. El ejemplo más extremo es probablemente la diuina ironia que le servía a Escoto Eriúgena, en Occidente, para interpretar en un sentido no sólo diferente sino contrario al literal el texto de la Escritura. ${ }^{13}$ Esto no significa que no lo creyera. Prueba, sin embargo, que no lo tomaba at face value. Por extensión, y así como la cuestión de la precisión histórica tenía una importancia ínfima o inexistente, es verosímil que ningún bizantino tomara la hagiografía at face value.

${ }^{10}$ J. Dummer, «Griechische Hagiographie», en F. Winkelmann - W. Branden, Quellen zur Geschichte des frühen Byzanz, Berlin, Akademie Verlag, 1990, pp. 284-296, aquí p. 290 (mis itálicas).

${ }^{11}$ Ch. Messis, «Fiction and/or Novelization in Byzantine Hagiography», en S. Efthymiadis (ed.), The Ashgate Research Companion to Byzantine Hagiography, vol. II, Farnham, Ashgate, 2014, pp. 313-341, aquí p. 313. Más matizado, Hippolyte Delehaye afirmó en un caso análogo: «La personnalité de $\mathrm{S}^{\text {te }}$ Sébastiana échappe au contrôle de l'histoire», H. Delehaye, «Saints de Thrace et de Mésie», Analecta Bollandiana 31 (1912), pp. 161-300, aquí p. 254. En efecto, nada impide que un dato histórico subsista por un azar en la conservación de las fuentes únicamente en la hagiografía; considerarlo falso (o «ficticio») sin mayor análisis puede ser un error de método.

12 Kaldellis, «Emergence», p. 115: «By fiction I don't mean any narrative or information that is unhistorical, even that which is recognized by readers as unhistorical».

${ }^{13}$ Véase E. Jeauneau, «Jean Scot et l'ironie», en sus Études érigéniennes, Paris, Brepols, 1987, pp. 323-337. Esta diuina ironia aparece también en el oriente helenoparlante. Así, por ejemplo, en un sermón pseudo-crisostómico sobre las malas mujeres (De decollatione

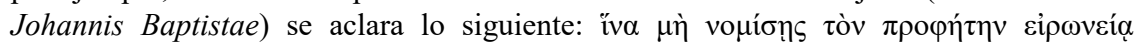

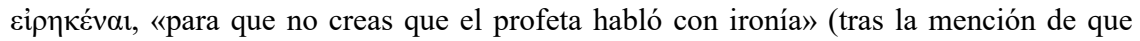
conviene convivir con un león o una serpiente antes que con un mala mujer; el sermón presupone, desde luego, que es concebible que un profeta se exprese de modo irónico), Patrologia Graeca 59, col. 486, 7-8. Curiosamente, también Escoto refería la ironía divina a la cuestión de la mujer y la relación entre los sexos. 
2. Quizá la exploración de los procedimientos, temas y funciones de los textos sea más productiva que una pregunta directa por su ficcionalidad, especialmente cuando ésta se centra en criterios de precisión histórica, en la creencia supuesta de una audiencia y en la relación entre texto y referente según era percibida por autor y lector. El enfoque propuesto en este artículo no excluye la pregunta por la ficcionalidad, si el investigador la juzga relevante: los rasgos distintivos de textos que una comunidad dada, antigua o moderna, considere, grosso modo, ficción (por ejemplo, en esta comunidad imaginaria: épica, tragedia, novela), pueden, en efecto, compararse con los rasgos distintivos de géneros que tradicionalmente se le oponen (crónicas, historiografía). En cualquier caso, la perspectiva de esta contribución subraya que, ya para los críticos antiguos y medievales, lo esencial para distinguir la historia de la épica o de la tragedia no es la historicidad sino los mecanismos narrativos; ${ }^{14}$ importa poco que los llamemos ficticios o de otro modo, si aclaramos en qué consiste exactamente su diferencia. Esta perspectiva, por lo demás, tiene la ventaja de presentar un continuum más amplio en torno a la problemática de la ficcionalidad, sin limitarse a un debate por el «sí» o por «no».

Una palabra sobre metodología. El presente modelo tiene mucho en común la narratología «natural» de Monika Fludernik, ${ }^{15}$ cuyo enfoque es más apto para esta disciplina que el de la narratología formalista clásica por varios motivos. Por un lado, se ocupa de la narración «natural», es decir, la episódica y menos estructurada (presente, por ejemplo, en los relatos orales, «conversational storytelling» [p. 10]); inútil señalar que gran parte de la producción bizantina es, precisamente, poco estructurada y episódica (las crónicas, numerosas vidas de santo, etc.). Por el otro, se ocupa de una narratividad no centrada en la trama (plot), que podría incluso faltar, sino en la implicación emocional de los personajes o el lector («This radical elimination of plot from my definition of narrativity is based on the results of research into oral narrative, where [...] the emotional involvement with the

14 «According to the mainstream critical opinion as represented by the grammarians and rhetoricians, the difference between history and epic had nothing to do with what we might label "historicity" (whether something had happened or not), but was rather a question of the mode of treatment, the degree of "fictiveness" which was applied in the narrating", D.C. Feeney, "Towards an Account of the Ancient World's Concepts of Fictive Belief», en C. Gill - T.P. Wiseman (eds.), Lies and Fiction in the Ancient World, pp. 230-244, aquí p. 233. Sobre la irrelevancia en última instancia del concepto de ficción bizantina, véase el final de este artículo; lo mantengo en el desarrollo por razones argumentativas. Ciertamente, numerosos autores estiman no solo que el concepto de ficción es productivo, sino que es también apto para la literatura medieval; así por ejemplo F.P. Knapp, Historie und Fiktion in der mittelalterlichen Gattungspoetik (I). Sieben Studien und ein Nachwort, Heidelberg, C. Winter, 1997; F.P. Knapp, Historie und Fiktion in der mittelalterlichen Gattungspoetik (II). Zehn neue Studien und ein Vorwort, Heidelberg, C. Winter, 2005.

${ }^{15}$ M. Fludernik, Towards a «Natural» Narratology, London - New York, Routledge, 1996. 
experience and its evaluation provide cognitive anchor points for the constitution of narrativity» [p. 13]); esto es particularmente atractivo en una literatura como la bizantina, donde la trama suele brillar por su ausencia, sin que esto signifique que la obra en cuestión no requiera una lectura narratológica. Asimismo, la perspectiva de Fludernik es histórica desde sus inicios y no se ocupa predominantemente del realismo «clásico» del siglo XIX; también en este aspecto tiene más que Genette para aportar a los estudios bizantinos. Por último, Fludernik, propone ocuparse de la narratividad y directamente dejar de lado el concepto de ficcionalidad, algo especialmente apropiado para los primeros siglos de Bizancio: «My proposals $[\ldots]$ tend towards entirely disregarding the concept of fictionality and the fictional [...]. Fictionality is here explicitly divorced from its traditional referential reading in the familiar opposition of fiction vs. historical (rather than logical or literal) truth» (pp. 39-40). En particular, este último punto es central. En lo que sigue, en efecto, no me pronuncio sobre la inexistencia de la ficción hasta el s. XII en Bizancio sino, más bien, sobre la dudosa productividad del concepto de ficción, y posiblemente no solo en Bizancio. En efecto, se trata de una quaestio iuris más que de una quaestio facti.

El lector notará que, aparte de Fludernik, tengo una deuda obvia con Erich Auerbach, Mijaíl Bajtín, Eleazar Meletinsky y Gérard Genette. En particular, la poética tipológico-comparativa de Meletinsky, e implícitamente también la de Auerbach, es central en este proyecto.

Finalmente, cabe señalar que mi propuesta es más empírica que la de Fludernik o Meletinsky. En líneas generales, intento únicamente proveer una grilla teórica utilizable en el análisis de textos concretos. Sólo para dejar en claro en qué estoy pensando, doy una lista provisoria y programática de varios de los principales rasgos que incluiría una grilla de ese tipo. Todas las categorías conciernen a la narratividad, y varias ponen el acento en la mímesis antes que en la eventual ficcionalidad; muchos de los rasgos pueden ser pertinentes en más de una categoría a la vez:

a. La temporalidad de los relatos. A título de ejemplo, la temporalidad épica (y la mítica en general) suele estar separada por una «distancia ideológica absoluta» del presente del lector; la novela se sitúa en una suerte de presente desplazado. Esta temporalidad épica tiende a reaparecer en los relatos de mártires de época tardía, mientras que la novelesca se percibe en varios relatos de santos que no fueron mártires; ambas temporalidades se diferencian de la de las crónicas. ${ }^{16}$

${ }^{16}$ T. Fernández, «Hagiografía, épica y novela», Temas Medievales 23 (2015), pp. 81-88. La oposición entre las temporalidades épicas y novelescas se apoya en el marco teórico de Bajtín. Kaldellis, por su parte, parece identificar el mito con la ficción; «fiction in Byzantium was already a function of "mythical" writing [...] myth acted fairly consistently as an 
Preguntas subsidiarias: ¿pueden ordenarse los eventos temporalmente? ¿Hay contradicciones cronológicas? También las clásicas preguntas narratológicas sobre el orden de secuencias narrativas elementales, la diferencia entre histoire y récit, etc.

b. La espacialidad.$^{17}$ ¿El espacio es homogéneo? ¿Es discontinuo? ¿Está jerarquizado de acuerdo a principios supra-espaciales? ${ }^{18}$ ¿Tiene alguna presencia la perspectiva geométrica? ¿Cuál es la cosmovisión? ¿Se trata de un mundo cerrado, de una totalidad orgánica? ¿La totalidad se completa en el propio mundo o fuera de él? ¿Qué espacios se mencionan, cuáles se minimizan? Preguntas más particulares, como la importancia que tienen los baños públicos tanto en determinadas obras bizantinas como en los cuentos de hadas rusos, deben analizarse en este marco (y no pueden resolverse por una mera referencia a la «realidad externa»). ${ }^{19}$

c. Las modalidades de entramado. Existen recursos estructurales típicamente asociados a ciertos géneros y a cierto modo de codificar los eventos, los personajes, etc. ${ }^{20}$ Por ejemplo: el uso de prólogos, digresiones y discursos en determinado tipo de historiografía; el uso exclusivo del discurso directo en la tragedia; la

enabler of the fictive stance» (Kaldellis, «Emergence», p. 125-126). En este marco, también sus diferentes temporalidades se equiparan. Así, «Mythic time and space were separate from that of lived experience but strangely analogous to it» (Kaldellis, «Emergence», p. 126); acto seguido menciona como representantes del «mito» a la tragedia y a la épica, que por ende serían ficciones. Desde la perspectiva de Bajtín, por el contrario, la temporalidad mítica tiene características diferenciales frente a la temporalidad de la novela, y ésta última tiene más rasgos asociados a la «ficción» que la épica o la tragedia.

${ }^{17}$ Sobre el reciente interés de los bizantinistas sobre el tema, cf. M. Kulhánková, «Zwischen Wüste und Welt: die Konstruktion des Raumes in den byzantinischen erbaulichen Erzählungen», Byzantinische Zeitschrift 108 (2015), pp. 715-734. De esta misma autora véase Das gottgefällige Abenteuer. Eine narratologische Analyse der byzantinischen erbaulichen Erzählungen, Červený Kostelec, 2015 (el artículo de la Byzantinische Zeitschrift es retomado como capítulo 3). Véase también el volumen reciente de M.-L. Ryan - K. Foote - M. Azaryahu, Narrating Space / Spatializing Narrative: Where Narrative Theory and Geography Meet, Columbus, 2016. Cupane, «Passeggiata», p. 71, observa: «Spazi narrativi diversi possono evocare, tramite realismo e / o straniamento realtà ideologicamente diverse e funzionare, così Agapitos (p. 285), come "traits of conscious fictionality").

${ }^{18}$ Por ejemplo: en la Vida de Espiridón el universo geográfico de varios episodios se ordena en torno a la iglesia, para subrayar su carácter de centro en la comunidad. Cf. T. Fernández, «Espacialidad y perspectiva en la Vita Spyridonis atribuida a Leoncio de Neápolis (s. VII)», en Stromata 68.3/4 (2012), pp. 221-235; Idem, «Geografía simbólica en la Vita Spyridonis», Ordia prima 13 (2014), pp. 139-162.

${ }^{19} \mathrm{Cf}$. A. Berger, Das Bad in der byzantinischen Zeit, München, Institut für die Byzantinistik und neugriechische Philologie der Universität, 1982; sobre la importancia de los baños en los cuentos de hadas rusos, M. Schneider (ed.), Russische Zaubermärchen, Stuttgart, Reclam, 2003, p. 198.

${ }^{20}$ Véase P.A. Agapitos, Narrative Structure in the Byzantine Vernacular Romances (tesis doctoral; Cambridge, 1990). 
brevedad y dramatismo en el cuento popular, etc. Pregunta subsidiaria: ¿busca el relato generar intriga? ${ }^{21}$

d. El punto de vista. ¿Quién es el narrador? ¿Narra eventos que no puede conocer? ¿Qué focalización predomina? ¿Aparecen comentarios explícitos del autor, como en cierta historiografía? ¿Hay una moralidad obvia? ¿Subyace una visión unificada de la religiosidad ortodoxa? ¿Presupone una lectura literal o favorece la interpretación figurativa? ¿El tono es serio, irónico, cómico? ¿Se habla seriamente de las clases bajas? ¿Se le presta atención a hechos sociales como el mayorazgo o el minorazgo, la endogamia y la exogamia, etc?

e. El tipo de personaje: ¿héroe sobrehumano? ¿Animal parlante? ¿Noble, plebeyo, huérfano? ¿Existen personajes bien individualizados, se insiste en sus características propias, en su historia personal, en sus procesos mentales? ¿Hay acceso directo a la subjetividad de los personajes? ${ }^{22}$ ¿Cuál es la relación entre la interioridad de los personajes y el mundo exterior? ${ }^{23}{ }$ Encuentra y dirige su propia aventura o ésta le viene impuesta? ${ }^{24}$ ¿Cómo se presenta al adversario: como un igual, como inferior? ¿Cuál es el lugar del criminal y el demente? A título de ejemplo: la posición del loco en la épica (incluso noniana) o en la tragedia (incluso en Bacantes) es muy distinta de la que aparece en los evangelios o en la Vida de Simeón el loco de Leoncio de Neápolis. ${ }^{25}$

${ }^{21} \mathrm{O}$, más en general, la función de la «tríada narrativa» (suspenso/curiosidad/sorpresa) de Meir Sternberg: «I define narrativity as the play of suspense/curiosity/surprise between represented and communicative time», «Telling in Time (II): Chronology, Teleology, Narrativity», Poetics Today 13/3 (1992), pp. 463-541, aquí p. 529.

22 «Tous les modes d'accès à la subjectivité du personnage [...] constitueraient des indices du statut fictionnel du texte. Le monologue, le style indirect libre, la focalisation interne signaleraient ainsi la fiction», C. Montalbetti, «Fiction, réel, référence», en Littérature 123. Roman Fiction (2001), pp. 44-55, aquí p. 50. Por supuesto, este «indicio de ficcionalidad» se verifica en gran parte de la historiografía clásica y medieval, que sin embargo no suele considerarse ficticia. Sobre la exageración de la importancia, por parte de algunos representantes de la narratología cognitiva, de la importancia de acceder a los procesos mentales de los personajes, cf. J. Grethlein, «Is Narrative "The Description of Fictional Mental Functioning"? Heliodorus Against Palmer, Zunshine \& Co.», Style 49/3 (2015), pp. 257-284.

${ }^{23}$ El conflicto entre el «bello espíritu» y el mundo es un ejemplo clásico. Sobre el mundo como «segunda naturaleza» del protagonista de la novela, cf. G. Lukács, Théorie du roman, Paris, Éditions Gonthier, 1963 (primera ed. alemana 1920), p. 56.

${ }^{24}$ Así distingue Meletinsky los cuentos occidentales de los chinos; en estos últimos, el evento «"capita" al protagonista, mentre nelle novelle classiche del Rinascimento occidentale esso è il risultato delle azioni del protagonista, tese verso uno scopo», E.M. Meletinski, Poetica storica della novella, Macerata, EUM, 2014 (primera ed. rusa 1990), p. 189.

25 «Quant à la folie, l'épopée l'ignore totalement si ce n'est comme l'incompréhensible langage d'un surmonde qui ne possède pas d'autre moyen de se manifester», G. Lukács, Théorie du roman, p. 55. 
f. Los motivos (loci) preponderantes. ${ }^{26}$ ¿Cuál es el contenido simbólico e ideológico de estos motivos? Sobre su problemática relación con la «realidad», recuérdese la primera oración de la monografía de Ruth Morse: «When the earlyfifteenth-century Augustinian Friar, John Capgrave, wrote that the corpse of Henry I (who had died in 1135) stank horribly, he expected his readers to understand a moral criticism. [...] A question such as, "But did Henry's corpse really smell?", might have seemed to him to miss the point of his description.» ${ }^{27}$ ¿Con qué otros textos y géneros discursivos dialogan estos loci? (Ver también infra, § $h, j$ )

g. La recepción y, ligado a ella, el tipo de circulación (¿en los mismos manuscritos que textos científicos? ¿en colecciones con otras obras? ${ }^{28}$, etc.) y su función (divertir, informar, convertir, etc.). ${ }^{29}$ ¿Intenta provocar una reacción determinada o impulsar determinada conducta, como apoyar un culto o promover la santificación de un personaje aun no santificado ${ }^{30}$ ¿Se presupone, por ejemplo,

${ }^{26}$ Cf. Th. Pratsch, Der hagiographische Topos (Berlin - New York, 2005), y A.-J. Festugière, «Lieux communs littéraires et themes de folk-lore dans l'Hagiographie primitive», Wiener Studien 73 (1960), pp. 123-152. También, entre otros, L. Rydén, «The BrideShows at the Byzantine Court - History or Fiction?», Eranos 83 (1985), pp. 175-191: el motivo, que evidenciaría una tradición oral, provendría de los cuentos de hadas. Entre los loci incluyo no sólo los topoi retóricos, sino los motivos literarios que codifican A. Aarne y S. Thompson (The Types of the Folktale. A Classification an Bibliography [Helsinki, Suomalainen Tiedeakatemia, 1961]), entre otros motivos.

${ }^{27}$ R. Morse, Truth and Convention in the Middle Ages. Rhetoric, Representation and Reality, Cambridge, Cambridge University Press, 1991. El lector moderno recuerda inmediatamente el ejemplo de Zósimo, el santo stárets de Los hermanos Karamázov: su cadáver tambión olía espantosamente. Aquí se ve la extraordinaria resiliencia de los topoi: en el caso de Dostoievski, el hedor del cadáver sin duda es «real», mientras el carácter de crítica moral a través de ese olor no es evidente; tal divergencia no se debe a la diferente relación que tiene con el referente la novela o el relato histórico, sino al sistema de expectativas en el que circulan.

${ }^{28}$ A. Billault «Les formes romanesques de l'héroïsation dans la Vie d'Apollonios de Tyane de Philostrate», Bulletin de l'Association Guillaume Budé 1/3 (1991), pp. 267-274, subraya la paradoja de que esta vida haya sido integrada en una colección de novelas antiguas como la realizada por Grimal; Kaldellis se asombra de que fragmentos de novelas aparezcan en los Excerpta historica; cf. infra, n. 73.

${ }^{29}$ E.C. Bourbouhakis «"Political” personae: the poem from prison of Michael Glykas: Byzantine literature between fact and fiction», Byzantine and Modern Greek Studies 31 (2007), pp. 53-75, aquí, p. 63: «No doubt the manner and occasion of performance helped condition the audience's expectations and assumptions about the literature they were about to hear. »

${ }^{30}$ Cf. V. Casamiquela Gerhold, «La dimensión política del género hagiográfico: La Vita Basilii, ¿una hagiografía imperial?», en Temas medievales 21 (2013), 29-47; la Vita Basilii, definida como «hagiografia imperial», sería «una hagiografía que no estuvo destinada a conmemorar u honrar la memoria de un santo ya declarado sino a promover la santificación 
un público de sentimientos altruistas, que no se alegra frente a la desgracia de nadie, ni siquiera del malvado?

h. ¿Qué intertextualidad predomina? ¿En qué relación se sitúa frente a los textos canónicos? ¿Qué grado de libertad tiene para alterar la tradición previa?

i. La creencia: ¿cree el lector en lo que lee? ¿En qué medida, por qué elementos? Ciertos rasgos internos al texto pueden ser indicios (o anticipadores) de la reacción del lector. Elementos que apuntan a un «effet de réel», en sentido barthesiano, ${ }^{31}$ pueden motivar una creencia, sin que haya una relación directa, por supuesto, entre el creer y la no ficción y el no creer y la ficción. Es sabido que un texto, para ser percibido como verdad, no necesita ajustarse a ningún referente externo aunque, según el caso, sí es necesario que el receptor lo asocie con un referente. A ese fin suelen servir las cronologías y genealogías: ${ }^{32}$ proveen de un «effet de réel». Así, por ejemplo, en la versión metafrástica de la Vita Spyridonis ${ }^{33}$ se señala que el santo visita a Constantino cuando eran cónsules Paulino y Juliano, 636 años después del reinado de Alejandro de Macedonia. La fuente para estos datos puede ser inexistente. Pero el proveer de datos precisos es fundamental, no por su eventual correspondencia con el referente sino para provocar en el público una reacción determinada.

j. El vínculo con el supuesto «orden de la cosas», en dos vertientes: 1) algo excesivamente probable ( $\varepsilon i \kappa o ́ \varsigma$ ) corre tradicionalmente el albur de ser sospechado de falta de historicidad (de haber sido pergeñado ad hoc por el autor de un relato); también algo que responde a un locus o algo que se ciñe demasiado prolijamente a una agenda ideológica preexistente $;{ }^{34}$ 2) un hecho de gran peso simbólico que podría tener una contrapartida histórica más probable suele ser interpretado en el sentido de esta contrapartida.

Ejemplo de lo primero: Festugière señala dos mecanismos habituales de los autores de hagiografía para dar valor a sus escritos: «le légende de la découverte d'un vieil écrit qui [...] en garantit la verité. [...] Et [...] la légende d'inspiration surnaturelle, obtenue généralement au cours d'une vision de songe. $\rangle^{35}$ Festugière se ve obligado a observar: «ces faits peuvent être exacts [...]. Mais la tradition du livre découvert par hasard est si populaire qu'on incline a soupçonner, ici encore,

de un individuo aún no santificado» (47): la definiría, por ende, su función, relacionada con la imagen de santidad futura.

${ }^{31}$ R. Barthes, «L'Effet de Réel», Communications 11 (1968), pp. 84-89.

${ }^{32}$ Cf. P. Veyne, ¿Creyeron los griegos en sus mitos?, Barcelona, Granica, 1987 (primera ed. francesa 1983), p. 131.

${ }^{33} P G$ 116, col. 429.

${ }^{34}$ Cf. M. Mullett, «No Drama», p. 231.

${ }^{35}$ Festugière, «Lieux communs», p. 124. De lo primero, da un ejemplo de la Vida de Hipatio de Calinico; de lo segundo, de la Vida de Eutimio de Cirilo de Escitópolis. 
une pure invention de l'auteur.» ${ }^{36}$ Que sea o no invención puede interesar poco y, en cualquier caso, no es una cuestión que pueda resolverse de modo unívoco; la presencia de un locus repetido y el modo en que éste produce un efecto en la audiencia lectora, que ya conoce el locus, en cambio, es de gran importancia (cf. $\S \mathrm{f})$.

Ejemplo de lo segundo: M. Kaplan recuerda el enkomion de Nicéforo a Teodoro de Sikeón, según el cual el emperador Heraclio en persona intervino en el traslado de las reliquias de Teodoro. Posiblemente dicho traslado haya sido realizado, como el de muchos otros santos, durante la invasión persa. «De là à transformer cette évacuation en urgence en un somptueux transfert ordonné par l'empereur, il n'y a qu'un pas aisément franchi par le premier rédacteur du transfert.» Kaplan debe conceder, sin embargo: «La réalité du transfert par Héraclius reste toutefois possible. ${ }^{37}$ Algo parecido puede decirse de los relatos donde se repiten esquemas trimembres o se producen simetrías extremas. Estos acercamientos complementarios no intentan dar cuenta de una desajuste entre el referente y el texto (que sí puede interesar al historiador) sino sobre la importancia de la tradición, las convenciones, las expectativas de una audiencia, los géneros o el «estilo de época ${ }^{38}$ para construir lo verosímil o lo simbólico, independientemente de que se asemejen o no a lo «efectivamente acaecido».

k. El tipo de causalidad (o de discontinuidad entre «causa» y «efecto»). Zumthor escribe que, si un evento es dado como producto o término de otro, las posibilidades son tres: «1. Continuité entre une cause et cet effet. / 2. Discontinuité (dans le temps, l'espace ou l'ordre de grandeur) entre cause et effet. / 3. Absence de cause.» ${ }^{39}$ Así, la existencia de hechos «imposibles» o míticos mostrará - al menos en ciertas épocas - el carácter maravilloso de un texto dado, salvo que se favorezca su interpretación figurada, como en los relatos de animales parlantes. ${ }^{40}$ (Aquí debe distinguirse cuidadosamente entre la causalidad aceptada por una audiencia dada y la causalidad considerada modernamente.) También debe plantearse la pregunta por las contradicciones, intencionales o no: si Roma a la vez puede ser y nunca haber sido, como postula Pedro Damiano, el paradigma es de

\footnotetext{
${ }^{36}$ Festugière, «Lieux communs», p. 125.

${ }^{37}$ M. Kaplan, «Hagiographie et histoire de la société», en P. Odorico - P. Agapitos, Les Vies des Saints à Byzance. Genre littéraire ou biographie historique?, Paris, Centre d'études byzantines, 2004, pp. 25-47, aquí p. 27, n. 6, para ambas citas.

${ }^{38}$ Cf. la introducción de P. Bürger en Theorie der Avantgarde, Frankfurt, Suhrkamp, 1974.

${ }^{39}$ P. Zumthor, Essai de poétique médiévale, Paris, Seuil, 2000 (1972), p. 171.

${ }^{40}$ Piénsese también en el locus de la inspiración sobrenatural, recordado por Festugière y citado supra, $\S \mathrm{j}$.
} 
cierto tipo; si Emma Bovary tenía los ojos a la vez noirs, bruns y bleus, de otro; ${ }^{41}$ las contradicciones cronológicas (cf. $\S$ a) pueden revelar falsedad o descuido en el caso de una crónica histórica, imprecisión del universo narrado en un policial de Sue Grafton, progresivas correcciones y adiciones en una obra como Illusions perdues, la realidad ambigua del material en Madame Bovary, etc. La posición exacta de la narración bizantina en este conglomerado de textos aún debe ser definida.

3. Para explicar la aplicación de los puntos anteriores, presento sumariamente un estudio de caso entre muchos posibles: los Milagros de Cosme y Damián, editados por Deubner. ${ }^{42}$ El culto de estos dos santos médicos - llamados anargyroi, «los que no toman dinero» - se desarrolló en Constantinopla en el siglo V. ${ }^{43} \mathrm{La}$ colección de milagros que nos ocupa, anónima y heterogénea, recoge textos de distintas épocas y es probablemente dos o tres siglos posterior al surgimiento del culto.

En la colección, la espacialidad ( $§$ b) es vaga, aunque tiene gran importancia; uno de sus fines es propagandístico, y resulta clara la intención de dar renombre a los santuarios de los santos ( $§ \mathrm{~g})$. Hay pocas referencias geográficas precisas y casi todas tienen una función cultual o eventualmente etiológica. En el milagro

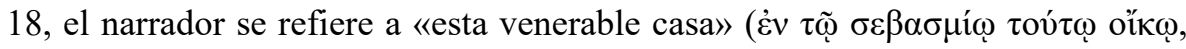
ed. Deubner 18, 144), como si el relato fuera leído allí mismo. La temporalidad ( $§$ a) es más vaga aún. La individualidad de los protagonistas no lo es menos ( $\S$ e). Además de carecer de características propias, ni siquiera se sabe con certeza si

${ }^{41}$ Véase C. Gothot-Mersch, «La description des visages dans Madame Bovary», en Littérature 15 (1974) pp. 17-26, aquí p. 20. En un principio, solía pensarse que la diferencia en la coloración de los ojos se debía a un error de Flaubert. Para un problema análogo en Homero, véase Ø. Andersen, «The Making of the Past in the Iliad», Harvard Studies in Classical Philology 93 (1990), pp. 25-45, especialmente pp. 29-30, con las observaciones de I. De Jong, «Homer and Narratology», en I. Morris - B. Powell (eds.), A New Companion to Homer, Leiden - New York - Köln, Brill, 1997, pp. 305-325, aquí p. 307.

${ }^{42}$ L. Deubner (ed.), Kosmas und Damian. Texte und Einleitung, Leipzig - Berlin, Teubner, 1907, con los textos suplementarios de E. Rupprecht (ed.), Cosmae et Damiani sanctorum medicorum Vitam e miracula e codice Londinensi, Berlin, Junker und Dünnhaupt, 1935. Traducciones: A.J. Festugière, Saint Thècle, saints Côme et Damien, saints Cyr et Jean (extraits), Saint Georges, Paris, Picard, 1971, pp. 82-213; J.M. Nieto Ibáñez, San Cosme y San Damián. Vida y milagros, Madrid, BAC, 2014, con la reseña de P. Cavallero en Minerva 28 (2015), pp. 392-394. Aquí como en el resto del artículo, las traducciones me pertenecen salvo indicación en contrario. Mi objetivo no es subrayar los elementos «ficticios» de la hagiografía. Para ello véase P. Roilos, «Phantasia and the Ethics of Fictionality in Byzantium. A Cognitive Anthropological Perspective», en Roilos (ed.), Medieval Greek Storytelling, pp. 9-30, especialmente pp. 21-26.

${ }^{43}$ Dos iglesias les estaban dedicadas, Zeugma y Kosmidion; cf. Kazhdan, Oxford Dictionary of Byzantium, s.u., vol. 2, New York - Oxford, Oxford University Press, 1991. 
existieron tres pares de santos con ese nombre, mucho menos a cuál de ellos refiere cada relato concreto; son los santos curadores por antonomasia y en ciertos ámbitos se los confunde con Cástor y Pólux (continuidad de función de personajes míticos paganos). En todos los relatos, los protagonistas son sobrehumanos: en particular por sus curas milagrosas, pero también por aparecerse en sueños, etc.

Entre los personajes se destaca una camella, curada por Cosme, que anuncia a la muerte del santo que éste se halla reunido con Damián, y que ambos han curado muchos animales $(\S \mathrm{e}){ }^{44}$

El universo es cerrado y orgánico, con interrelaciones extramateriales $(\S b)$. Hay lugar para la superstición y para la eficacia de procedimientos mágicos, siquiera mediatamente $(\S \mathrm{k})$. En el milagro 3, un hombre debe comer el pelo de

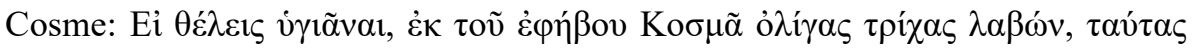

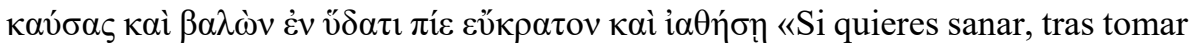
del joven Cosme unos pocos pelos, después de quemarlos y ponerlos en agua bebe ésta tibia y serás sanado» (ed. Deubner 3, 21-23). Poco antes se anunciaba que un cordero, en honor al santo, se llamaba Cosme. Aquí aparece otro motivo folclórico apenas modificado, el Rätselmotiv ( $(\mathrm{f})$ : la frase ambigua, en un principio mal comprendida, funciona como una adivinanza (basada en una homonimia que, por su parte, no es casual): de la primera interpretación, la de comer literalmente el pelo del santo, se pasa a la correcta, a saber, la necesidad de comer el pelo de Cosme el cordero, no Cosme el santo ( $§$ c: intriga y sorpresa). La medicina, ya no sólo la magia, es simpática: comer el pelo del cordero es un modo de acercarse a Cosme, mientras el cordero, por su parte, se llama Cosme en honor al santo.

La equivalencia simbólica que concede eficacia a los pelos del cordero llamado Cosme se manifiesta de otro modo en las imágenes: en el milagro 15, la paciente arranca de la pared la imagen de los santos, la mezcla con agua, la bebe y se cura (semejante poder curativo de la imagen, que opera por contacto, se aprecia en el milagro 13) (§ $\mathrm{k})$.

La magia, por su parte, reaparece de modo explícito en otro milagro, si bien no como realidad sino como medio de presionar a un paciente que se resiste a tomar la medida que requiere su curación (beber aceite de cedro). Dada su negativa, los santos le ordenan enterrar tres frasquitos con dicho aceite cerca del hipódromo al que, por añadidura, es adicto. Las autoridades lo descubren. Lo

\footnotetext{
${ }^{44}$ Sobre animales en la hagiografía y, en particular, los milagros que sobre ellos operan los santos, cf. Th. Pratsch, Der hagiographische Topos, pp. 286-289; véase también J.E. Spittler, Animals in the Apocryphal Acts of the Apostles, Tübingen, Mohr, 2008, y la venerable monografía de M. Landau, Die Quellen des Dekameron, Stuttgart, Scheible's, 1884, pp. 239-243 (sobre animales en hagiografía y en narrativa relacionada). Existennumerosas representaciones de la camella en la iconografía de los santos; cf. las reproducciones en H. Skroboucha, Kosmas und Damian, Recklinghausen, Bongers, 1965.
} 
aprisionan, acusándolo de magia. Para probar su inocencia, el hombre bebe el aceite, mostrando así que la pócima que enterraba no era maléfica. Al instante se cura y también lo liberan. El «castigo» (léase: su terror) basta también para curar su afición al hipódromo. ${ }^{45}$

La reforma del pecador, incluso doctrinario, también es frecuente. En el milagro 2, una mujer judía tiene cáncer. Para curarse, debe comer carne de cerdo. Justo antes de hacerlo (casi como sucedió con Abraham e Isaac: $\S$ h) se cura. Maravillada, se vuelve cristiana.

En el milagro 10 se recuerdan las palabras de Jesús (Lucas 15: 10): $\mu \varepsilon \gamma \alpha \dot{\lambda} \lambda \eta$

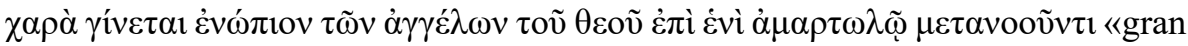
gozo hay delante de los ángeles de Dios por un pecador que se arrepiente» $(\S \mathrm{h})$, ed. Deubner 10, 75-76. Sin embargo, la tolerancia conoce límites. El narrador subraya la supuesta costumbre de las regiones orientales de quemar al extranjero ( $\left.\dot{\alpha} \lambda \lambda_{0} \varepsilon \theta v \eta ́ \varsigma\right)$ infiltrado en iglesia. Los cristianos de esa ciudad, sin miedo del ma-

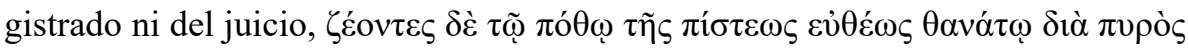

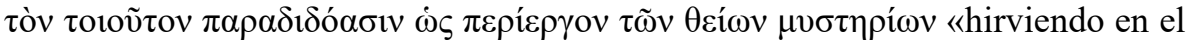
deseo de fe al instante entregan a éste [el pagano] a la muerte por fuego, por entrometerse en los divinos misterios» (ed. Deubner, 10, 51-52). Nueva simpatía mágico-verbal: hierven en la fe, queman al intruso. Nótese el tono con el que se aprueba el suceso, disculpable por el fervor de los creyentes ( $\S \mathrm{g}$ : presupone un público poco afecto a las concesiones frente al pecador, pese a la frase evangélica; ¿con qué nivel de literalidad la tomaban?).

La relación con los cuentos populares de otros tiempos y culturas es particularmente clara. Aparecen muchos puntos de contacto: la picardía (§ d), el humor $(\S \mathrm{d})$, la intriga (§ c), la separación tajante de buenos y malos (§ e), el castigo de estos últimos, la salvación / salud de quien acepta humildemente su error $(\S \mathrm{d})$; también el anonimato de los relatos y la recensión abierta $(\S \mathrm{g})$, las invocaciones el público $(\S \mathrm{g}),{ }^{46}$ la brevedad, la claridad doctrinaria que no admite claroscuros

${ }^{45} \mathrm{Cf}$. H. Magoulias, «The lives of Byzantine saints as sources of data for the history of magic in the sixth and seventh centuries A.D.: Sorcery, relics, and icons», Byzantion 37 (1967), pp. 228-269, aquí pp. 242-244.

${ }^{46}$ Sobre los distintos modos de dirigirse al público, véase la reseña de B. Emmrich a Nikolae Roshianu, Традиционные формуль сказки (Fórmulas tradicionales del cuento de hadas), en Jahrbuch für Volkskunde und Kulturgeschichte 20, n. F. 5 (1977), pp. 247-250, aquí p. 249: «1. Formeln, die die Aufmerksamkeit der Zuhörer wecken sollen [o, según el resumen inglés del libro de Rosijanu, p. 212: «Formulas by means of which one is trying to arouse the listeners' curiosity, enlisting thus their full attention»]; 2. Formeln, die die Aufmerksamkeit der Zuhörer prüfen (kontrollieren) sollen; 3. Übergangsformeln (zwischen einzelnen Episoden)», con el importante agregado de que, según Rosijanu, «diese Formeln an den mündlichen Tradierungsprozeß gebunden sind». 
(§ d), la unidad de efecto (§ c), el dramatismo (§ c). ${ }^{47}$ Por supuesto, elementos de cuento popular pueden encontrarse en todas partes, incluso, por no dar más que un ejemplo famoso, en la historiografía de Heródoto; basta con una historia general de la literatura griega para comprobarlo. ${ }^{48}$ Pero la función y frecuencia de esos elementos es muy distinta en las Historias y en los relatos de milagros, como un simple vistazo a la grilla permite apreciar.

Festugière, incansable lector de hagiografía, destaca los motivos del agón en

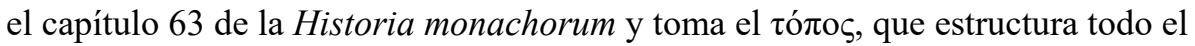
capítulo, como un indicio suplementario de la preeminencia del texto griego sobre el latino (el latino habría ordenado los elementos del relato popular de un modo más ajustado a la lógica de los hechos pero que, por ese mismo motivo, no hace honor al locus estructurante, en que se suceden discursos enfrentados) (cf. $\S \mathrm{f}, \mathrm{j}){ }^{49}$ En otra contribución, Festugière explica con sutileza los excesos en que incurren los santos para triunfar en el agón: «Tout cela ne brille pas par l'humilité et serait, au vrai, incompréhensible, du moins dans un tel ouvrage à la gloire des moines, si l'on manquait à percevoir, plus ou moins lointains, de vieux souvenirs de folklore païen, des échos, à peine atténués, de la $\varphi \imath \lambda o \tau \imath \mu i ́ \alpha$ grecque» ${ }^{50}(\S \mathrm{d}, \mathrm{e})$.

${ }^{47}$ En este artículo no distingo los mal llamados, en español, «cuentos de hada» [Märchen, fiabe] de las anécdotas, cuyos ejemplos paradigmáticos son sendas obras de los hermanos Grimm: por un lado los Märchen, por el otro sus Deutsche Sagen. Muy esquemáticamente, en los primeros no abundan las indicaciones espaciales y temporales concretas ni referencias al modo en el que se accede a la narración; los segundos son, al menos vagamente, históricos. Una última especificación: a diferencia de la novella, los Märchen no suelen tener un punto de giro claro.

${ }^{48}$ Por ejemplo, A. Lesky, Geschichte der griechischen Literatur, Bern - München, Francke, 1963, p. 180. Aún es útil la monografía de W. Aly, Volksmärchen, Sage und Novelle bei Herodot und seinen Zeitgenossen, Göttingen, Vandenhoeck u. Ruprecht, 1921. Para motivos folclóricos en la literatura antigua, véase Lelli, cit. infra, n. 50, quien también menciona el problema de qué puede considerarse «popular» en la cultura antigua. W. Schadewaldt, Die Anfänge der Geschichtsschreibung bei den Griechen, Frankfurt a. M., Suhrkamp, 1982), pp. 42-44, señala la presencia de fábulas de animales y de Novellen en un estrato preliterario, que considera prosaico («Die Fabel ist also eine ehrwürdige, rein prosaisch Literaturform [...]»); asigna a los Märchen un carácter igualmente prosaico (p. 39), distinto de la canción o la épica, y los contrasta con las Novellen. (Por supuesto, Schadewaldt estaba persuadido de que no había fábulas en Homero; ahora sabemos que ése no es el caso, como lo prueba M. Davies, «Homer and the Fable: Odyssey 21.293-306», Prometheus 27 [2001], pp. 193-210.) Este tipo de análisis, que tiene cierta venerabilidad en estudios clásicos, todavía debe llevarse a cabo de una manera sistemática en el ámbito bizantino, especialmente en el ámbito de la hagiografía y de la historiografía.

${ }^{49}$ Cf. A-J. Festugière, «Le problème littéraire de l'Historia Monachorum», Hermes 83/3 (1955), pp. 257-284, aquí pp. 272-277.

${ }^{50}$ Festugière, «Lieux communs», p. 144. Sobre la analogía entre diversos textos griegos y latinos y el folclore moderno, véase E. Lelli, «Folklorica», Hermes 142/1 (2014), pp. 95- 
En ciertos milagros de Cosme y Damián los santos aterrorizan al paciente (por ejemplo, en el milagro 1, con un escalpelo); es fácil imaginar el gozo del público ante estos hechos $(\S \mathrm{g})$.

El milagro 24, por su parte, aplica «unadulterated shock treatment» ${ }^{51}$ : los santos le ordenan en sueños a un paralítico que, si desea curarse, se acueste con una muda que, como él, dormía en la casa de los santos. Al paralítico le parece imposible que los santos requieran precisamente eso. Los santos insisten una segunda y una tercera vez, hasta que lo convencen. El paralítico se arrastra hacia la muda, la abraza. La mujer pierde al mismo tiempo el sueño y la mudez. Empieza a gritar. El paralítico, aterrado, huye corriendo. . Wortley arriesga una interpretación a su modo mitológica: «It is interesting to speculate whether the anecdote might not have originated in a genuine case of attempted rape at a place where deformed and diseased men and women seem to have slept in the same chamber» ${ }^{52}(\S \mathrm{j})$.

En el sexto milagro, el paciente no debe comer alimentos que empiecen con

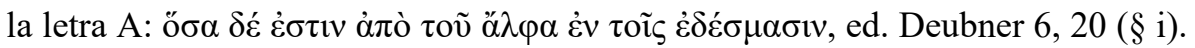
Aquí, como en muchos de los puntos mencionados, puede ponerse a prueba el principio de la fictive stance propuesto por Kaldellis: ¿acordaban autor y lector juzgar según criterios de precisión histórica la regla de los alimentos que empiezan con A? Una respuesta positiva sería, cuando menos, aventurada. Esto no significa que el texto en cuestión sea ficticio.

Los animales parlantes ( $\S$ e), aunque aquí no sean protagonistas, y la moralidad evidente ( $\S \mathrm{d})$, tienen puntos de contacto claro con las fábulas esópicas; el gozo con el daño del malvado ( $(\mathrm{e}, \mathrm{g})$ tiene mucho de narración popular y poco de evangélico.

Creo que la sumatoria de los elementos mencionados pone en entredicho la afirmación de que la hagiografía era tomada al pie de la letra. Las protestas contra la incredulidad del público, referidas en términos específicos y nada ambiguos,

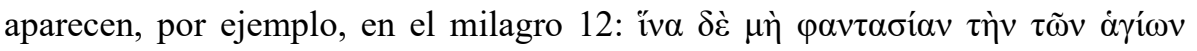
$\pi \alpha \rho \alpha ́ \sigma \tau \alpha \sigma ı v$ vo

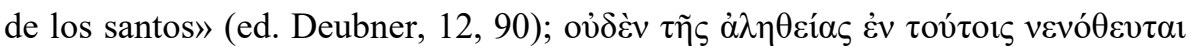
«en esto no se falta en nada a la verdad» (ed. Deubner, 12, 121-122). Curiosamente, el mismo Kaldellis escribió la más completa refutación moderna de que la hagiografía fuese tomada al pie de la letra, señalando que «hagiographers were

101; el artículo complementa dos contribuciones anteriores de Lelli sobre el mismo tema. En el área de la hagiografía: P. Boglioni, «Hagiographie et folklore. Quelques coordonnées de leur rapport», Florilegium 22 (2005), pp. 1-24.

${ }^{51}$ J. Wortley, «Three not-so-miraculous miracles», en sus Studies on the Cult of Relics in Byzantium up to 1204, Ashgate, Farnham, 2009, IX, pp. 159-168, aquí p. 165.

52 Wortley, «Three not-so-miraculous miracles», p. 165. 
open about the fact that they expected incredulity» y que «the ultimate sceptic [is] the (Christian) reader himself». ${ }^{53}$

Kaldellis debate si el escepticismo que los textos ponen en escena era real y presente en el auditorio medio o si se trataba de un artificio retórico para incitar al público a creer en los milagros sin necesidad de verlos. No se detiene en el problema de si la incredulidad tenía que ver con la desconfianza de cierta comunidad por un santo particular (por ejemplo, acusado de iconoclasta) o con un descrédito general sobre la posibilidad de milagros de cierto tipo. Es obvio que los enemigos políticos de un obispo no aceptarían sus poderes milagrosos; esto dice poco sobre la incredulidad de una audiencia y menos aún sobre la relación entre creencia y ficción. La mayor parte de los incrédulos que Kaldellis presenta son los malvados en el relato, se conviertan o no, y parecen en gran medida la encarnación de prejuicio negativos («todo lo que no es el buen oyente cristiano»). La observación de Kaldellis sobre Kopres (cap. 10, Historia monachorum) es de gran interés: "The problem is that Kopres' narratives really are fantastic, even by the standards of the genre»; ${ }^{54}$ lamentablemente, no queda claro cuáles son los estándares del género en materia de fantasía, ni cuál es su vínculo con la credulidad.

Sobre la cuestión de la relación entre creencia y «fantasía», vale la pena recordar una anécdota relatada por C. Lévi-Strauss. Un hechicero, en la primera tormenta de la temporada, es arrebatado por el trueno y llevado a varios kilómetro de distancia. Luego es devuelto a las inmediaciones de la tribu, despojado de sus adornos. ${ }^{55}$ La tribu se componía de dos grupos étnicos, y el hechicero intrigaba contra uno de ellos. Según este grupo, el hechicero pretextaba el evento del trueno para reunirse con el otro grupo. Lévi-Strauss subraya que el grupo hostil habría «asombrado mucho a los escépticos» al invocar una explicación tan verosímil, analizándola «con mucha fineza psicológica y sentido político», para desautorizar la experiencia del hechicero. Nadie afirmaba: el hechicero miente, ya que ningún

${ }^{53}$ A. Kaldellis, «The Hagiography of Doubt and Scepticism», en S. Efthymiadis: The Ashgate Research Companion to Byzantine Hagiography, vol. II, Farnham, Ashgate, 2014, pp. 453-477, aquí p. 463 (para ambas citas).

${ }^{54}$ Kaldellis, «Hagiography», p. 459: Patermouthios, según el relato de Kopres, «used to walk across the Nile, fly and teleport himself». Sobre un vuelo semejante, sólo que en una nube, cf. el texto eslavo recientemente publicado por S.A. Ivanov, «The Right Hand Fetid, the Left Unclean. An Unknown Byzantine Spiritually Beneficial Tale», Analecta Bollandiana 133 (2015), pp. 249-255, aquí p. 255. Wortley describe de modo sucinto la peculiaridad de Patermouthios, sin considerarla fantástica: «He is one of the very few fathers ever credited with raising the dead (albeit temporarily) and the only one said to have delayed the setting of the sun on one occasion», en J. Wortley, «The Tale of the Converted Robber», Studies on the Cult of Relics in Byzantium up to 1204, Farnham, Ashgate, 2009), X, pp. 119-240, aquí p. 220.

${ }^{55}$ C. Lévi-Strauss, Anthropologie structurale, Paris, Pocket, 2003 (1958), pp. 194-195. 
trueno puede llevarlo en andas. Por el contrario, esa relación con las fuerzas naturales era una experiencia corriente; «que, dans le cas particulier, il [sc. el hechicero] ait prétexté son pouvoir pour dissimuler une activité profane, c'est le domaine de la conjecture et l'occasion d'appliquer la critique historique..) ${ }^{56}$

Si se nos permite considerar el parlamento del hechicero como un relato, destacaremos que no se lo puede considerar falso (ni mucho menos ficticio) por un componente que, a los ojos de un moderno, es claramente fantástico. Si algunos indígenas desconfiaron, no fue por la violación de las leyes naturales, sino por motivos circunstanciales. Aun si fuera falso, el relato no sería fantástico. ${ }^{57}$ Para estos indígenas escépticos, el relato se ubicaría en la categoría de las res fictae quae tamen fieri potuit (= argumenta) Un receptor occidental moderno, si no estuviera prevenido, lo consideraría en cambio fabula $(\S \mathrm{j}, \mathrm{k})$.

Cuando Kaldellis agrupa clases diversas de escepticismo (por ejemplo, el motivado por la confesión herética de un monje determinado o el causado por la incredulidad de un feligrés endurecido) y adiciona, como justificación suplementaria del escepticismo, el carácter aparentemente legendario de cierto relato ortodoxo, parece superponer niveles narrativos (y de creencia) que deben distinguirse cuidadosamente, como hace Lévi-Strauss.

Una última observación sobre el tema, ligada al psicoanálisis. Habitualmente, escribe Freud en su estudio sobre el Hombre de los lobos, confundimos el fenómeno de que una percepción se presente ante la conciencia con la pertenencia a un sistema psíquico que llamamos también «conciencia». Esta confusión es inocua en el hombre maduro (deberíamos agregar: occidental y moderno), pero no en el niño. ${ }^{58}$ Puedo dar un ejemplo inspirado en P. Veyne. El niño puede constatar que su padre es Papá Noel (percepción presente ante la conciencia) y seguir creyendo en Papá Noel (no pertenencia de la percepción en el sistema conciente). En este caso no es operativa la oposición verdadero / falso. No sólo por la existencia de una instancia intermedia: este tertium quid modifica los polos opositivos verdadero / falso.

Es cierto que posteriormente, y con claridad en ciertos autores del siglo XII, la distinción entre estos polos puede resurgir con fuerza. Baste con mencionar el caso de Eustacio de Tesalónica, recientemente estudiado por Baukje van den

${ }^{56}$ C. Lévi-Strauss, Anthropologie structurale, pp. 195-196.

${ }^{57}$ Meletinsky diferencia entre lo sobrenatural como natural y lo sobrenatural como extraordinario, dando un ejemplo intermedio, el del Märchen; no menor en esta diferencia es la perspectiva de la audiencia, pero también la del investigador moderno: «Il fantastico nella fiaba sta tra il concetto di sopranaturale come naturale (nel mito) e allo stesso tempo straordinario (come nella novella)»; Meletinskij, Poetica storica della novella, p. 5.

${ }^{58}$ S. Freud, Zwei Kinderneurosen, Frankfurt a. M., Fischer, 1996, p. 217. 
Berg. ${ }^{59}$ Eustacio pone el acento en la «hipocresía» y la performance, que puede ser digna aunque implicara un engaño. La distinción no es tanto entre verdad y falsedad como entre falsedades aceptables (las que tienen un fin noble) e inaceptables; la épica y el drama tienen una dosis de falsedad. Desde una perspectiva moderna, esto podría acercarlos a la ficción, y eso parece pensar Van den Berg. Así, afirma por ejemplo: «Ancient tragedy and Homeric poetry are largely fictional or semi-historical at most» (p. 32), dando por sentado que lo ahistórico se acerca a lo ficticio. Sin embargo, la autora observa también que «Eustathios seems to get quite close to a concept of fiction, in which plausibility is an important means to enable the audience to suspend their disbelief» (p. 30, n. 47). En esta formulación alternativa resulta plausible lo que se cree no por ser real sino por una suspensión de la incredulidad. Vale la pena notar, de todos modos, que la suspensión de la incredulidad puede volver plausibles incluso elementos intrínsecamente inverosímiles como los de la mitología.$^{60}$ Esto depende de una particular noción de plausibilidad, que combina diversos criterios. En efecto, según Van den Berg, «Eustathios' analysis of plausibility in Homeric poetry indicates that, for him, plausibility results from both correspondence to extratextual reality and consistency within the microcosm of the Iliad and the world of Greek mythology in general» (p. 32). El primer criterio es el del referente; el segundo, que apunta a la consistencia, permite ampliar las fronteras. La composición literaria, que para Eustacio pertenece de pleno derecho al reino de la retórica, ${ }^{61}$ puede ser plausible o implausible. Esto tiene poco que ver con que sea verdadera o falsa, por mucho que, para ser plausible, a menudo requiera de «bueno engaños».

La plausibilidad y la verosimilitud tienen poco en común con la «ficción». Los requisitos de plausibilidad son igualmente fuertes en, por ejemplo, la retórica forense; la $\pi \imath \theta \alpha v o ́ \tau \eta \zeta$, que tiene un peso tan grande en Aristóteles, no se relaciona principalmente con la épica o el drama. Inversamente, los progymnasmata, en muchos puntos cercanos a la «ficción», suelen no tener mayores preocupaciones de plausibilidad salvo en lo referido a lo apropiado, $\pi \rho \dot{\pi} \pi \mathrm{ov}$, para determinado personaje. La suspensión de la incredulidad (si esta formulación de Coleridge es apropiada para el mundo bizantino), por su parte, tampoco explica

${ }^{59}$ B. van den Berg, "“The Excellent Man Lies Sometimes”: Eustathios of Thessalonike on Good Hypocrisy, Praiseworthy Falsehood, and Rhetorical Plausibility in Ancient Poetry», Scandinavian Journal of Byzantine and Modern Greek Studies 3 (2017), pp. 15-35.

${ }^{60}$ «Some more marvellous events clearly do not correspond to reality and, thus, may seem implausible» (p. 29). Sin embargo, resultan plausibles en el sistema del que forman parte.

${ }^{61}$ Cf. Van den Berg, "“The Excellent Man” », pp. 16-17. Para la relación entre la retórica y la novela de amor de amor en particular, cf. I. Nilsson, «Romantic Love in Rhetorical Guise: the Byzantine Revival», en C. Cupane - B. Krönung, Fictional Storytelling in the Medieval Eastern Mediterranean and Beyond, Brill, Leiden - Boston, 2016, pp. 39-66. 
específicamente la épica, el drama o la novela, ya que igualmente bien podría lograrse, si bien por otros medios, en géneros que habitualmente no se suele vincular a la «ficción», como la hagiografía.

Van den Berg no discute puntualmente la definición de ficción, ni en el mundo bizantino ni fuera de él; más bien supone que la ficción existe, que tiene una relación complicada con el referente externo (suele ser ahistórica, por ejemplo) y que puede debatirse si aparece en determinado texto. Un enfoque semejante se halla en A. Pizzone. ${ }^{62}$ Según esta autora, desde la perspectiva de Eustacio la épica es «akin to fiction»; en efecto, «Homeric epic is presented as the locus of authorial creativity, as regards both the narrative material to be found in Phantasia's scrolls and the techniques through which Homer re-edits the story». ${ }^{63}$ Aquí, la distinción entre verdad y falsedad es secundaria, aunque deba ser tomada en cuenta. La

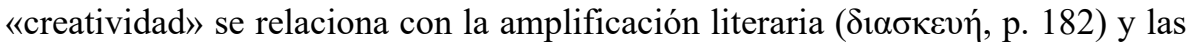
comparaciones ( $\pi \alpha \rho \alpha \beta o \lambda \alpha i ́$, p. 183). Ninguna de estas técnicas se asocian necesariamente a la «ficción», ni tienen connotaciones de falsedad, aunque sí puedan disparar una determinada expectativa por parte de un público determinado (que no está acostumbrado a encontrarlas, por ejemplo, en textos que pretenden dar cuenta de manera espontánea de una realidad fáctica).

A diferencia de las contribuciones de Van den Berg y de Pizzone, el presente artículo intenta poner en tela de juicio la utilidad del concepto mismo de ficción en el ámbito bizantino; no si se manifiesta en determinado período o en determinada obra. Por lo demás, la visión del siglo XII, según la discuten Van den Berg y Pizzone, probablemente no sea aplicable a épocas anteriores, donde suele aparecer una distinción menos estricta entre verdadero o falso y el afán de plausibilidad tiene otras reglas.

Tras este largo recorrido por la verdad, la falsedad, la plausibilidad y su relación con el concepto de ficción, querría detenerme en la problemática de la

${ }^{62}$ También Cupane, «Passeggiata», Bourbouhakis «"Political” personae» o, como hemos visto, Kaldellis. La formulación de C. Cupane y B. Krönung resume este punto de vista: «in Byzantium [...] fictional writing in its proper sense is not to be found until the late 11th century», en «Introduction», C. Cupane - B. Krönung, Fictional Storytelling in the Medieval Eastern Mediterranean and Beyond, Brill, Leiden - Boston, 2016, pp. 1-17, aquí p. 8. Desde mi perspectiva, el final del siglo XI efectivamente significa un corte decisivo. Menos claro me parece, en cambio, que ese corte pueda explicarse por el surgimiento de la «ficción». Más bien prefiero detenerme en los cambios de narratividad y subrayar, aparte de las diferencias, las contniuidades con la producción anterior, verbigracia con la tradición retórica de las etopeyas o con los modos de representar la espacialidad y la temporalidad en la hagiografía.

${ }^{63}$ A. Pizzone, «Lady Phantasia's "Epic” Scrolls and Fictional Creativity in Eustathios' Commentaries on Homer», Medioevo greco 14 (2014), p. 182. 
causalidad y la creencia bizantinas ( $(\mathrm{i}, \mathrm{k})$, volviendo al período temprano y medio-bizantino.

Un estudio sobre la ruptura obvia de la noción de causalidad, no sólo moderna (que interesa muy subsidiariamente), puede ganar en perspectiva si se complementa con las categorías de J. Le Goff. Debería estudiarse, como ya se hizo para el Occidente latino, la relación entre la hagiografía y lo sobrenatural. La tipología de L'imaginaire médiéval puede ser un buen punto de partida. Existen, según Le Goff, tres ámbitos principales: mirabilis (maravilloso), magicus (mágico), miraculosus (milagroso) ${ }^{64} \mathrm{El}$ primero es el más amplio $\mathrm{y}$, al menos originalmente, incluía al tercero, específicamente cristiano. El occidente latino no siempre diferenció, con términos distintos, miraculosus de mirabilis; lo mismo ocurre en Bi-

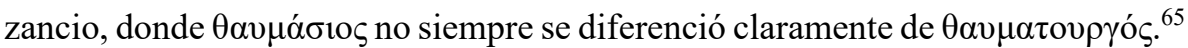
El uso de una misma palabra, sin embargo, no excluye las distinciones. La diferencia conceptual es a menudo clara. Así, lo propiamente maravilloso - es decir, lo maravilloso no milagroso - suele tener un componente precristiano. Este punto preciso, el de lo maravilloso no milagroso, sería útil para diferenciar niveles de creencia en el género hagiográfico más allá de lo históricamente fiable o no: una cosa es el dato cronológico aparentemente preciso, otro el milagro en la tradición evangélica, otro el elemento sobrenatural de cuento popular o fábula esópica. Ninguno de los tres (salvo en ciertos casos el primero) es históricamente preciso, aunque los tres puedan ser considerados «realistas» entre comillas, de modo muy diverso; la fábula, por ejemplo, en tanto su verdad y enseñanza moral es fácilmente accesible. ${ }^{66}$

Sin duda, no todos los elementos eran creídos del mismo modo (sin que esto implique un escepticismo activo) ni todos por el mismo público (§ i). Alguien que recordara al menos vagamente las críticas al uso supersticioso de las imágenes difícilmente tomaría al pie de la letra los relatos sobre la eficacia curativa de los retratos de los santos. ${ }^{67}$ En los Milagros de Cosme y Damián, como en muchas

${ }^{64}$ J. Le Goff, L'imaginaire médiévale, Paris, Gallimard, 1985, p. 17-28.

${ }^{65}$ Sobre la acusación de practicar $\mu \alpha \gamma$ í en vez de $\theta \alpha v \mu \alpha \tau o v \rho \gamma i ́ \alpha$, cf. Kaldellis, «Hagiography», p. 457. Para un estudio de lo maravilloso en la "ficción" bizantina tardía, cf. C. Cupane, "Other Worlds, Other Voices: Form and Function of the Marvelous in Late Byzantine Function», en P. Roilos (ed.), Medieval Greek Storytelling. Fictionality and Narrative in Byzantium, Wiesbaden, Harrassowitz, 2014, pp. 183-202.

${ }^{66}$ Véase por ejemplo Cupane, «Passeggiata», pp. 85-86.

${ }^{67}$ Sobre el complicado modo que un santo tenía para operar en el mundo tras su muerte, y la relación entre su alma y su cuerpo (necesario, según ciertas concepciones, para el milagro), véase el artículo de Dirk Krausmüller, en particular sus lúcidas reflexiones sobre De statu animarum post mortem de Eustracio de Constantinopla, D. Krausmüller, «Sleeping Soul and Living Corpses», Byzantion 85 (2015), pp. 143-155; también G. Dagron, «L'ombre 
colecciones hagiográficas, se verifican no sólo hechos milagrosos, sino maravillosos en sentido amplio (la camella parlante) o mágico-supersticiosos (§ k). Pensar que un lector los toma igualmente al pie de la letra, o que es igualmente escéptico frente a los tres, es una simplificación excesiva.

En cualquier caso, la cuestión del entramado particular y la función del texto es tan central para la discusión de su narratividad y, subsidiariamente, si esto interesa al investigador, de su relación con géneros considerados ficticios (o de su propia ficcionalidad), como la cuestión de la creencia por parte de un auditorio dado. Sin embargo, y aun si se considerara sólo la creencia, no parece adecuado asignarla o negarla globalmente para todos los lectores de hagiografía.

4. Hemos visto que Kaldellis provee de dos técnicas para detectar la ficción: la de la fictive stance y la de no tomar at face value. Según la primera, es ficción lo que autor y lector no juzgan según criterios de precisión histórica; según la segunda, lo que un lector no toma al pie de la letra. ${ }^{68} \mathrm{La}$ superposición de modelos parece presuponer que alguien toma al pie de la letra lo que considera históricamente preciso. Esta presuposición, que no es cierta en tiempos modernos, es particularmente inapropiada para la narrativa bizantina. En este punto es necesario retomar la cuestión recién planteada con respecto a los Milagros de Cosme y Damián. ¿En qué creían los bizantinos? Responder «en lo históricamente preciso», «en lo verdadero», o incluso «en lo esencialmente verdadero» es un desplazamiento de la pregunta, no una respuesta. ${ }^{69}$

Em la contribución de Kaldellis hay dos pasajes clave para etender su paradigma. En uno se refiere a H. White: «Excited by what he took to be a discovery that there was rhetoric in historical narratives, the theorist Hayden White famously concluded that history was, after all, a kind of fiction».$^{70}$ White, sin duda, puede haber exagerado el aspecto subjetivo-fenoménico de la historiografía y, $a$ fortiori, de cualquier relato escrito. Pero el vicio contrario - dar por sentada la cognoscibilidad y transparencia de su objeto de estudio - está todavía más

d'un doute. L'hagiographie en question, $\mathrm{VI}^{\mathrm{e}}-\mathrm{VII}^{\mathrm{e}}$ siècle», Dumbarton Oaks Papers 46 (1992), pp. 59-68, esp. p. 67-68

${ }^{68}$ Cf. supra, $\S 1$.

${ }^{69}$ Una excelente discusión breve sobre la verosimilitud y la creencia en el cuento de hadas aparece en la reseña de Roshianu, p. 248 (cit. supra, n. 46); en ningún caso puede estimarse que simplemente la audiencia no creía en ellos, pero tampoco que meramente creía. Para la cuestión de la plausibilidad, véase las contribuciones de Van den Berg, «"The Excellent Man" », Pizzone, «Lady Phantasia» y Bourbouhakis «"Political” personae», mencionadas supra.

${ }^{70}$ Kaldellis, «Emergence», p. 122; cf. supra, n. 3, e infra, n. 74. 
difundida entre los estudiosos del período bizantino. ${ }^{71}$ En este sentido es pertinente, para la investigación actual, el epígrafe de Bourdieu que encabeza este artículo.

En el segundo, refiriéndose a ¿Creían los griegos en sus mitos? de P. Veyne, Kaldellis afirma: «The book's radically postmodern epistemology does not vitiate all of its insights.» ${ }^{72}$ Voy a detenerme en esta «epistemología radicalmente posmoderna», que vicia no todos pero sí, podemos suponer, la mayor parte de los hallazgos de Veyne.

En general, Veyne mostró con particular claridad que entre los griegos la cuestión de la creencia no podía zanjarse por un simple juicio de verdad, ya que ni necesariamente creían en lo verdadero ni dudaban de lo que hubieran podido considerar falso. Suspender el juicio de verdad no siempre implicaba dejar de creer; la tradición tenía una función inconcebiblemente poderosa.

Numerosos bizantinos del período temprano y medio, por su parte, tendían a asumir como parádosis todo lo que tenían de buena fuente. No era su práctica evaluar pausadamente los contenidos para decidir si eran históricos o no. Por este motivo, el hecho de que los copiaran en determinadas colecciones no implica, al contrario de lo que piensa Kaldellis, ${ }^{73}$ que los tomasen al pie de la letra, sino que su modalidad de creencia era más matizada y generosa (menos metonímica, menos literal) que la moderna.

A diferencia de Veyne, Kaldellis no se detiene en la relación entre verdad, historicidad y creencia. Pero precisamente problematizar este punto (cf. infra, § 5) le habría permitido una base más rica para su discusión sobre la ficción bizantina, incluso limitándose a una postura que tome por centro lo que un lector o un autor supuestamente cree o no cree. ${ }^{74}$ Aun si bastara con decir que un género dado,

${ }^{71}$ Una discusión vivaz sobre el tema, oponiendo los historiadores «butterfly» a los historiadores «caterpillar», aparece en I. Ševčenko, «Two Varieties of Historical Writing», History and Theory 8/3 (1969), pp. 332-345: entre otras cosas, los primeros consideran a la historia una provincia de la literatura, los segundos entienden que el hecho histórico es intrínsecamente reconstruible.

${ }^{72}$ Kaldellis, «Emergence», p. 126, n. 50.

73 "And it is rather alarming that fragments of Iamblichos' novel Babiloniaka are found in the Excerpta de sententiis of Konstantinos VII, a collection that is otherwise based on historical works!», Kaldellis, «Emergence», p. 122; cf. supra, n. 28. Una lectura atenta de Veyne probablemente habría salvado al erudito del adjetivo «alarmante» y del signo de admiración.

${ }^{74}$ Para la cuestión del referente desde la postura de Veyne, véase ¿Creyeron los griegos en sus mitos?, p. 112, n. 113, donde menciona «otro problema: el de las supuestas relaciones entre un texto y su referente». Precisamente el carácter problemático de «estas supuestas relaciones», que puso sobre el tapete White, es soslayado por Kaldellis (pese a la importancia indirecta que le concede en la cuestión del pacto de lectura entre autor y lector). 
como el hagiográfico, simplemente no es ficción porque el lector lo cree, quedarían por definir las modalidades de creencia de los bizantinos, que en muchos aspectos clave, y en ocasiones de modo antiintuitivo, no coinciden con las de otros sujetos. $^{75}$

«Como escribe Ducrot en Dire et ne pas dire, la información es una ilocución que sólo se cumple si el destinatario reconoce al locutor competencia y honestidad, de tal manera que una información se ubica, desde el principio, fuera de la alternativa verdadero-falso», señala Veyne. ${ }^{76}$ Esta idea puede matizarse; pero sin duda es útil para poner en perspectiva la idea de que la alternativa «creer»- «no creer» depende de una evaluación según criterios de precisión histórica. Recordemos al pasar que, según Kaldellis, «[a]ny narrative that conformed to social expectations stood a good chance of being accepted as true». ${ }^{77} \mathrm{Si}$ bien esta formulación parece acercarse a la de Veyne, no resulta del todo compatible con la definición kaldelliana de la postura ficticia, que vale la pena recordar por entero: «the mode of writing and reading in which it is understood on all sides (by both authors and readers) that a particular work is not meant to be evaluated by criteria of historical accuracy». ${ }^{78}$ Tengamos en cuenta, adicionalmente, que la hagiografía no es ficción porque fue tomada «at face value by contemporary readers». ${ }^{79}$ Ficción pasa de ser aquel texto que no se evalúa con criterios de precisión histórica a aquél que un lector no cree (no toma at face value) y no acepta como verdad. En cualquier caso, las expectativas sociales van por un lado, la precisión histórica por otro, la creencia por un tercero, por más que no sean enteramente independientes.

Quizá sea posmoderno poner en duda la cognoscibilidad inmediata de la «realidad» y separar analíticamente distintos modos de creencia o diferentes circulaciones de verdades; si es así, quizá sea la hora de que los estudios bizantinos, como sus pares occidentales, se tornen modestamente posmodernos.

5. ¿Creían los bizantinos en sus milagros? En gran medida, es indudable que sí, por más que deba diferenciarse entre distintos tipos de milagro y de audiencia. ¿Esto convierte a los relatos hagiográficos en no ficción? Evidentemente no. Tampoco implica que, inversamente, deban ser ficción. Con esta constatación podemos examinar las concepciones del investigador moderno sobre los géneros discursivos.

\footnotetext{
${ }^{75}$ Cf. P. Roilos, «Phantasia and the Ethics of Fictionality in Byzantium», en: Roylos (ed.), Medieval Greek Storytelling, pp. 9-30, especialmente p. 16.

${ }^{76}$ P. Veyne, ¿Creían los griegos en sus mitos?, p. 52, n. 21.

${ }^{77}$ Kaldellis, «Emergence», p. 118.

${ }^{78}$ Kaldellis, «Emergence», p. 115.

${ }^{79}$ Kaldellis, «Emergence», p. 116.
} 
La negativa de Kaldellis a ocuparse de los géneros parece tener su contrapartida en afirmaciones como la de H.R. Jauss según quien, en Occidente (pero la frase podría aplicarse igualmente a Bizancio), el estilo y el tema eran más centrales para la audiencia que los géneros. ${ }^{80}$ La semejanza entre ambos eruditos, sin embargo, es ilusoria. Jauss pretende corregir la atención exagerada por los géneros, no desterrarlos del análisis. Kaldellis, en cambio, cita apreciativamente a G. Bowersock: «with works of imaginative literature there is nothing more ruinous for historical understanding than genre theory [or] a search for antecedents. ${ }^{81}$

Inevitable recordar aquí la primera página de la Présentation a la Théorie de genres compilada por Todorov y Genette. Los autores fustigan la teoría, en su opinión ya superada, que favoreció «une approche historiciste et positiviste, pour laquelle rien ne devait être considéré au-delà des individus, des œuvres singulières et des circonstances empiriques - oubliant apparemment que rien n'est plus profondément historique, en art et en littérature comme probablement ailleurs, que l'émergence, le succès, la permanence ou le dépérissement d'une tradition.» ${ }^{82}$ Así justifican la necesidad de detenerse en los géneros discursivos.

Esta contribución pretende subrayar que tener en cuenta los géneros, al menos para extraer un puñado de rasgos significativos, permitirá definir con mayor precisión campos específicos que posteriormente, si se juzga útil, podrán ser considerados como asociados a la ficción o no. En esto no hago más que seguir los pasos de Delehaye, según quien «le groupement systématique des motifs légendaires fournis par les documents hagiographiques» proveería resultados análogos a los de comparar estos motivos en historias y crónicas, mediante el procedimiento «de les mettre en parallèle avec d'autres du même genre». ${ }^{83} \mathrm{Si}$ bien esta contribución sólo presenta una grilla, no un agrupamiento sistemático, y si bien Delehaye consideraba que la filiación de estos motivos era menos importante que su potencial para descartar la historicidad de lo narrado $(\S \mathrm{j}, \mathrm{f})$, el hecho principal subsiste: la comparación entre elementos semejantes, o entre textos y géneros análogos, es central para delimitar sus rasgos distintivos. En este punto hay continuidad entre Delehaye y Todorov - Genette.

Probablemente, la pregunta sobre la ficción bizantina deba precisar en primer término su propia perspectiva. Hemos visto que Kaldellis intenta tomar el punto de vista de los bizantinos, minimizando los prejuicios (Vorurteile en la

${ }^{80}$ H.-R. Jauss, «Littérature médiévale et théorie des genres», Poétique 1 (1970), pp. 79-101; reimpreso en Genette - Todorov (cit. infra, n. 82), .

${ }^{81}$ G.W. Bowersock, Fiction as History: Nero to Julian, Berkeley, University of California Press, 1994, p. 14; Kaldellis, «Emergence», p. 122.

${ }^{82}$ G. Genette - T. Todorov, Théorie des genres, Paris, Seuil, 1986, p. 7.

${ }^{83} \mathrm{H}$. Delehaye, Les légendes hagiographiques, Bruxelles, Bureaux de la société des Bollandistes, 1906, p. 31. 
hermenéutica gadameriana) del investigador. Este primer posicionamiento se dispara en múltiples direcciones: hemos visto que, primero, la fictive stance depende únicamente del autor y el lector bizantinos, como si este punto de vista fuera el único relevante y, por añadidura, transparente para los investigadores posteriores; segundo, que la hagiografía no es ficción por haber sido tomada at face value. La perspectiva del lector moderno es abiertamente dejada de lado, al menos en teoría. Sin embargo, Kaldellis utiliza como baremo de la fictive stance la historical accuracy que, como hemos visto, es una preocupación del erudito moderno, no del hombre medieval. «Die Naivität des sogenannten Historismus besteht darin, daß er [...] im Vertrauen auf die Methodik seines Verfahrens seine eigene Geschichtlichkeit vergißt.. ${ }^{84}$

$\mathrm{Al}$ mismo tiempo, para un bizantino la «ficción» no existía como tal; estaba inextricablemente ligada a otros modos de narratividad y no era intuitivamente diferenciable, se la llame $\pi \lambda \alpha \dot{\sigma} \sigma \mu \alpha, \mu \tilde{v} \theta$ o $\varsigma$ o de otro modo. (Por eso mismo el título de la presente contribución es «Sobre el concepto de ficción bizantina» y no «Sobre el concepto bizantino de ficción»: en efecto, no existió ningún concepto bizantino de ficción.) Esto no significa que el problema de la ficción bizantina deba ser dejado de lado. Pero habría que explicitar, primero, en qué medida otras prácticas o conceptos bizantinos se superponen con el de «ficción». ${ }^{85}$ En segundo término, en qué medida vale la pena extrapolar al mundo bizantino el concepto de ficción. El reparo que puede aplicársele a esta extrapolación, de todos modos, no es el de anacronismo, como espero demostrar en el siguiente párrafo.

En un estimulante ensayo, la socióloga E. Esposito parte de la siguiente constatación: la teoría de la probabilidad nace en la segunda mitad del siglo XVII; la novela moderna, y con ella la ficción en sentido estricto, también. Esposito está persuadida de que la «realidad verosímil» es una ficción, como se manifiesta en el título de su libro, ${ }^{86}$ la especificidad de la ficción no es definida por su relación imaginada con un referente. Mutatis mutandis, considero que un enfoque como el de Esposito sería productivo para preguntarse por la productividad (no tanto por la validez) del concepto de ficción bizantina. ${ }^{87}$ La pregunta a plantearse quizá sería: ¿es adecuado asegurar que en tal o cual período la ficción existe o no, sin antes

${ }^{84}$ Wahrheit und Methode, Tübingen, Mohr, 1965, p. 283.

${ }^{85}$ El problema de la verosimilitud y la plausibilidad, ampliamente estudiado en los últimos tiempos (cf. supra, n. 59) no se confunde con el de la ficción, por más que en todos ellos aparezca, al menos subsidiariamente, la relación entre verdad, falsedad y creencia.

${ }^{86}$ E. Esposito, Die Fiktion der wahrscheinlichen Realität, Frankfurt a.M., Suhrkamp, 2007. En una línea semejante, N. Luhmann se refiere directamente a una realidad ficticia, y a la diferencia entre realidad y ficción dentro de la realidad (Schriften zur Kunst und Literatur [Frankfurt a.M., Suhrkamp, 2008], pp. 280-281; de un escrito inédito de 1995).

87 Véase también la aportación de M. Fludernik, cit. supra, n. 15. 
asegurarse de que el concepto de ficción es adecuado para dicha narrativa? Con esto retomamos la discusión sobre el anacronismo. No es el anacronismo lo que invalida el concepto de ficción bizantina. Algunos conceptos modernos se revelan productivos para estudiar períodos en los que el concepto no existía. Uno de ellos es el de economía, extremadamente productivo pese a no haber existido en el mundo clásico en ningún sentido moderno, como ha demostrado ampliamente $\mathrm{M}$. Finley. El problema de rótulos como «barroco», «racionalista» o, quizá, «ficticio» para distintos períodos de Bizancio es su nula productividad y la imposibilidad de ponerlos a prueba. Una afirmación como «Leoncio de Neápolis es machista» no es tanto verdadera o falsa como indecidible y, por ende, inútil. La afirmación «la ficción bizantina no existe hasta el siglo XII» probablemente pertenezca a una categoría similar aunque, sustancialmente reformulada, podría resultar iluminadora.

Las categorías estéticas del hombre bizantino son inaccesibles de modo directo. La ilusión de tomar fielmente su punto de vista pone en juego la ruinosa antítesis que aparece como epígrafe de este artículo: objetivismo es también el intento de rescatar la subjetividad de un sujeto histórico sin tomar en consideración la propia subjetividad del intérprete. De todos modos, y a diferencia de los bizantinos mismos, Kaldellis lee los textos bizantinos como literatura. En esto quizá resida el mayor acierto de su notable contribución.

Antes de tomar partido por la existencia o no de la ficción bizantina, quizá convenga detenerse en la narratividad del período y en su relación con el realismo (o la mímesis de la realidad) en sentido lato. Es sabido que Auerbach, en su libro sobre la mimesis en Occidente, no provee ejemplos del mundo bizantino. Colmar esa laguna, integrando la representación de la realidad bizantina en un continuum más amplio, que no anulará su autonomía y su especificidad sino que, por el contrario, las pondrá de relieve, parece una misión más urgente que la de tomar textos individuales y afirmar «éste es ficción», «éste no».

La lista de rasgos pertinentes para definir la narratividad específica de un texto, presentada más arriba, intenta volver más clara la relación entre textos y géneros, y entre textos y cosmovisiones. Pese a su carácter provisorio e incompleto, puede ser útil para una teoría de la mímesis bizantina. Si se concluye que tal y cual texto, por analogía, por ejemplo, con la novela antigua y la fabulística medieval tardía, es ficticio, no hay ninguna objeción. Pero eso será secundario frente a la tarea de establecer con precisión los rasgos diferenciales de esos textos y la relación que guardan con otras obras, en un marco que contemple otras épocas, incluyendo la propia del intérprete. 